\title{
Cataract extraction in leprosy patients
}

\author{
V A RAO \& V K KAWATRA \\ Department of Ophthalmology, Jawaharial Institute of Post-Grad- \\ uate Medical Education and Research, Pondicherry-605 006, India
}

\author{
Accepted for publication 12 August 1987
}

Summary Forty-one eyes of 36 leprosy patients were operated on for cataracts. The ocular findings contributing to blindness among the 41 operated eyes were corneal opacity $(26 \cdot 8 \%)$, old uveitis $(36 \cdot 6 \%)$ and glaucoma $(7 \cdot 3 \%)$. Shallow anterior chamber in the early postoperative period was observed in $26.8 \%$ of cases. The use of systemic corticosteroids definitely reduced the incidence of postoperative uveitis $(2 \cdot 4 \%)$. Thirty-seven $(90 \cdot 24 \%)$ eyes showed improvement in their visual acuity of two Snellen's lines or more after surgery. We conclude that cataract surgery may help in rehabilitation of already disabled and handicapped leprosy patients.

\section{Introduction}

No other disease is surrounded by so much prejudice in the eyes of the general public as leprosy. The total number of cases throughout the world is now placed at over 12 million. ${ }^{1}$ It is estimated that about $25 \%$ cases of both lepromatous and nonlepromatous leprosy patients ultimately show ocular involvement ${ }^{2}$ and if given enough time all patients with lepromatous leprosy will develop ocular complications. ${ }^{3}$ With the introduction of sulphones and other chemotherapeutic drugs in the last two decades, leprosy rarely causes death in the absence of secondary infections and certain other complications. ${ }^{2}$ Ocular lesions are seen more frequently with increasing age and duration of the disease ${ }^{4}$ Chronic iritis produces iris atrophy with small nonreacting pupil which exaggerates the visual impairment caused by lens changes and corneal opacities. ${ }^{5}$

Blindness in leprosy superimposes an intolerable burden and seriously threatens a patient's quality of life. Cataract extraction is perfectly feasible in leprosy patients provided the disease is quiescent. ${ }^{2,6,7}$ In the present study, the visual outcome along with operative and postoperative complications of cataract extraction in 41 eyes of 36 leprosy patients have been evaluated.

\section{Materials and methods}

Thirty-six leprosy patients were admitted in the Department of Ophthalmology, JIPMER, Pondicherry from March 1983 to August 1986 for cataract surgery. Leprosy was diagnosed by clinical signs and laboratory investigations. The patients with positive skin test were not admitted 
for surgery. All patients had received some form of antileprosy therapy earlier. Complete ocular examination was done including visual acuity, tonometry, slit-lamp examination and funduscopy.

All the patients were given dapsone $100 \mathrm{mg} /$ day from the day of surgery. Systemic steroid (prednisolone $40 \mathrm{mg} /$ day) was started in patients with old uveitis and tapered within 2 to 3 weeks after surgery. Lens extraction was achieved with cryo-probe and $0.25 \mathrm{ml}$ each of Dexamethasone and Gentamicin was in jected subconjunctivally after surgery. Complete iridectomy was accomplished opposite clear cornea in patients with central corneal opacity and also in miosed, nonreacting pupils. In patients with synechiae, synechiotomy was performed before extracting the lens. All the patients were followed up for a maximum period of 6 months.

\section{Observations}

Forty-one eyes of 36 leprosy patients (lepromatous 29, borderline 2 and tuberculoid 5) were operated for cataract. There were $26(72 \cdot 3 \%)$ males and $10(27 \cdot 7 \%)$ females with mean age of $55 \cdot 8$ and 47.5 years respectively. Twenty-four patients had severe involvement of the face and/or limbs. Visual acuity for distant vision of $6 / 60$ or more in the better eye with best correction was present in $12(33.3 \%)$ patients only. Out of 72 eyes, $5(6.9 \%)$ had no perception of light (anterior staphyloma 3 , phthisis bulbi 1, glaucoma with ciliary staphyloma 1). The preoperative and postoperative visual acuity in 41 eyes is shown in Figure 1. Thirty-seven (90.24\%) eyes showed improvement in their visual acuity of two Snellen's lines or more after surgery. Four $(9 \cdot 75 \%)$ patients showed no improvement (panophthalmitis 1, total glaucomatous optic atrophy 2, central leucomatous corneal opacity 1). An analysis of ocular findings contributing to blindness in 41 operated eyes is shown in Table 1. The operative and postoperative complications are shown in Table 2.

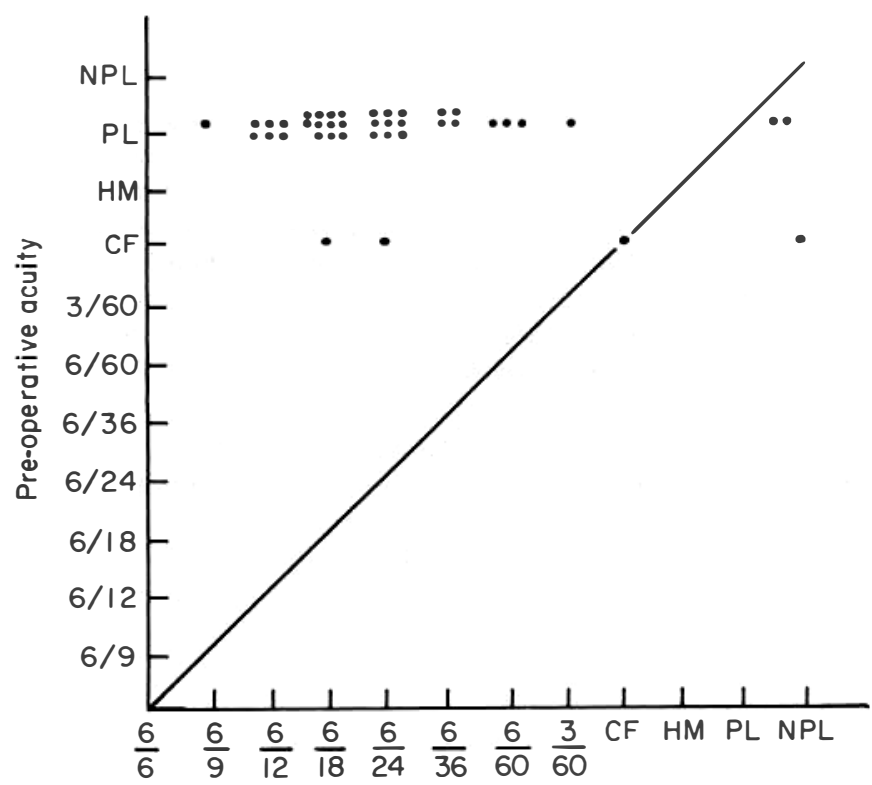

Figure 1. Postoperative visual acuity in 41 eyes. 
Table 1. Ocular findings contributing to blindness among 41 operated eyes.

\begin{tabular}{lc}
\hline & $11(26 \cdot 8 \%)$ \\
Corneal opacity & $15(36 \cdot 6 \%)$ \\
Old uveitis & $3(7 \cdot 3 \%)$ \\
$\begin{array}{l}\text { Glaucoma (Chronic simple glaucoma 1) } \\
\text { and secondary glaucoma 2) }\end{array}$ \\
\hline
\end{tabular}

Table 2. Operative and postoperative complications in 41 lens extractions.

\begin{tabular}{lr}
\hline Unplanned extracapsular extraction & 5 \\
$\quad$ (In two capsule was removed) & \\
Vitreous loss & 1 \\
Postoperative uveitis & 1 \\
Postoperative hyphaema & 5 \\
Postoperative shallow anterior chamber & 11 \\
Panophthalmitis & 1 \\
After cataract & 3 \\
\hline
\end{tabular}

\section{Discussion}

The reported incidence of ocular involvment in leprosy varies from $5.87 \%$ to $80 \%$ in India and $47 \%$ to $74.2 \%$ abroad. ${ }^{7}$ The eyes are involved in leprosy in 4 ways: $i$, abnormal exposure of the eyes secondary to involvement of the 5 th and 7 th cranial nerves; ii, inflammation of the eyes secondary to the infiltration by the leprosy bacillus; iii, infiltration of the eyes and/or eyelids by the leprosy bacillus; and iv, complication secondary to involvement of neighbouring structures - eyelids, lacrimal glands and nasolacrimal drainage system. ${ }^{8}$ The visual loss in leprosy is due to the combined effect of corneal and lens opacities associated with chronic uveitis. ${ }^{5}$ The crystalline lens is never directly invaded by bacilli in a leprotic lesion and the lens changes are those seen in a normal ageing population. ${ }^{9,10}$ A complicated cataract may develop after chronic uveitis and acute iritis associated with hypersensitivity. ${ }^{9,11,12}$ Toxic cataract may develop with the use of corticosteroids in lepra reaction. ${ }^{2,13}$ ffytche $^{6}$ found that the average age of the patients 61.5 years for men and 62.7 for females represented a lower average age than that of non-leprosy patients undergoing cataract surgery. In the present series, the average age of the patients 55.8 years for men and $47.5 \mathrm{for}$ females, suggests that there are other factors apart from senile changes in lens which definitely accelerate the development of cataract.

Functional blindness is defined as visual acuity for distant vision of $6 / 60(20 / 200)$ or less in the better eye with correction. Blindness is a grave problem among leprosy patients. Courtright et al. ${ }^{14}$ reported $11 \%$ of leprosy patients with functional blindness in South Korea, and in $4.3 \%$ of eyes, there was no perception of light. Advanced cataract was observed in approximately $5 \%$ of eyes. Prasad et al. ${ }^{7}$ reported $76 \%$ success of cataract surgery in leprosy patients and in most of the cases (73.2\%), the improvement of vision was up to 3 lines of Snellen's chart. In another series, ffytche ${ }^{6}$ reported visual improvement in $90 \%$ of lepromatous leprosy patients and in $60 \%$ this improvement was 2 Snellen's lines or more. In the present series, $90 \cdot 2 \%$ eyes showed visual improvement of two or more Snellen's lines.

ffytche $^{6}$ reported higher incidence of operative complications in 81 eyes which included 14 vitreous loss and 14 unplanned extracapsular extraction as compared to present series of 5 
unplanned extracapsular extraction and one vitreous loss in 41 eyes. This may be due to different techniques of lens extractions - forceps combined with expression in the former and cryo-extraction in the latter. Prasad et al. ${ }^{7}$ reported a higher incidence of postoperative uveitis (16\%) as compared to $2.4 \%$ in the present series. This might be due to use of systemic steroids which prevented the reactivation of old uveitis. Surprisingly $26.8 \%$ eyes showed shallow anterior chamber in the immediate postoperative period. All resolved within 3 to 5 days with conservative management. This might be due to various factors like the use of systemic steroids and corneal anaesthesia, due to involvement of ophthalmic division of the trigeminal nerve which results in delayed wound healing.

Blindness is the most expensive of all causes of serious disablement. It not only makes an individual handicapped and miserable but also puts unnecessary burden on the community. This is more so in leprosy patients who might be disabled due to deformities of hands and feet. Cataract surgery provides a reasonably safe surgical answer to restore the vision in the leprosy patients who are blind due to opacification of lens.

\section{References}

${ }^{1}$ WHO Expert Committee on leprosy. Technical Report Series No. 607, 1977.

${ }^{2}$ Dharmendra. Leprosy Bombay: Kothari Medical Publishing House: Vol. I, 1978; pp 143, 513, 519, 559, 685.

${ }^{3}$ Harley RD. Ocular leprosy in Panama. Am J Ophthal, 1946; 29: 295-316.

${ }^{4}$ Gupta CP. Eye complications in leprosy. Lepr India, 1976; 4: (suppl), 529.

${ }^{5} \mathrm{ffytche}$ TJ. Role of iris changes as a cause of blindness in lepromatous leprosy. Br J Ophthal, 1981; 65: 231-9.

${ }^{6}$ ffytche TJ. Cataract surgery in the management of late complications of lepromatous leprosy in South Korea. Br J Ophthal, 1981; 65: 243-8.

7 Prasad VN, Narain M, Mukhija RD, Pandey ON. Cataract surgery in leprosy patients. Afro-Asian J Ophthal, 1986; 5: 94-7.

8 Joffrion VC, Brand MF. Leprosy of the eye-a general outline. Lepr Rev, 1984; 55: 1-12.

${ }^{9}$ Kolmes WJ. The eye of leprosy. Trans Ophthal Soc UK, 1957; 81: 397-420.

${ }_{10}$ Weekeroon L. Ocular leprosy in Ceylon. Br J Ophthal, 1969; 53: 457-65.

${ }^{11}$ Choyce DP. The diagnosis and management of ocular leprosy Br J Ophthal, 1969; 53: 217-23.

${ }^{12}$ Shields JA, Waring GO, Monte LG. Ocular finding in leprosy. Am J Ophthal, 1974; 77: 880-90.

13 Peyman GA, Sanders DR, Goldberg MF. Principles and practice of O phthalmology. London: W.B. Saunders; Vol. I, 1980; 519.

${ }^{14}$ Courtright P, Green R, Pilarski R, Smucny J. A survey of the eye complications of leprosy in South Korea. Lepr Rev, 1984; 55: 229-37. 